\title{
Prevalence of complaints of arm, neck and shoulder among computer office workers and psychometric evaluation of a risk factor questionnaire
}

\author{
Shahla Eltayeb*1,2, J Bart Staal ${ }^{1}$, Janneke Kennes ${ }^{3}$, Petra HG Lamberts ${ }^{4}$ and \\ Rob A de Bie ${ }^{1}$
}

\begin{abstract}
Address: ${ }^{1}$ Maastricht University, Department of Epidemiology and Caphri Research Institute, Maastricht, The Netherlands, ${ }^{2}$ Ahfad University for Women, School of Psychology and Preschool Education, Omdurman, Sudan, ${ }^{3}$ Lievensberg Hospital, Emergency Department, Bergen op Zoom, The Netherlands and ${ }^{4}$ Public Health Service South Limburg, Geleen, The Netherlands
\end{abstract}

Email: Shahla Eltayeb* - s_eltyeb@hotmail.com; J Bart Staal - Bart.Staal@EPID.unimaas.nl; Janneke Kennes - jannekekennes@gmail.com; Petra HG Lamberts - Petra.Lamberts@ggdzl.nl; Rob A de Bie - RA.deBie@EPID.unimaas.nl

* Corresponding author

Published: 14 July 2007

BMC Musculoskeletal Disorders 2007, 8:68 doi:10.1 186/147/-2474-8-68

This article is available from: http://www.biomedcentral.com/I47/-2474/8/68

(c) 2007 Eltayeb et al; licensee BioMed Central Ltd.

This is an Open Access article distributed under the terms of the Creative Commons Attribution License (http://creativecommons.org/licenses/by/2.0), which permits unrestricted use, distribution, and reproduction in any medium, provided the original work is properly cited.
Received: 7 March 2007

Accepted: I4 July 2007

\begin{abstract}
Background: Complaints of Arm Neck and Shoulder (CANS) represent a wide range of complaints, which can differ in severity from mild, periodic symptoms to severe, chronic and debilitating conditions. They are thought to be associated with both physical and psychosocial risk factors. The measurement and identification of the various risk factors for these complaints is an important step towards recognizing (a) high risk subgroups that are relevant in profiling CANS; and (b) also for developing targeted and effective intervention plans for treatment. The purpose of the present study was to investigate the prevalence of CANS in a Dutch population of computer workers and to develop a questionnaire aimed at measuring workplace physical and psychosocial risk factors for the presence of these complaints.

Methods: To examine potential workplace risk factors for the presence of CANS, the Maastricht Upper Extremity Questionnaire (MUEQ), a structured questionnaire, was developed and tested among 264 computer office workers of a branch office of the national social security institution in the Netherlands. The MUEQ holds 95 items covering demographic characteristics, in addition to seven main domains assessing potential risk factors with regard to (I) work station, (2) posture during work, (3) quality of break time, (4) job demands, (5) job control, and (6) social support. The MUEQ further contained some additional questions about the quality of the work environment and the presence of complaints in the neck, shoulder, upper and lower arm, elbow, hand and wrist. The prevalence rates of CANS in the past year were computed. Further, we investigated the psychometric properties of the MUEQ (i.e. factor structure and reliability).

Results: The one-year prevalence rate of CANS indicated that $54 \%$ of the respondents reported at least one complaint in the arm, neck and/or shoulder. The highest prevalence rates were found for neck and shoulder symptoms $(33 \%$ and $31 \%$ respectively), followed by hand and upper arm complaints (1I\% to $12 \%$ ) and elbow, lower arm and wrist complaints $(6 \%$ to $7 \%$ ). The psychometric properties of the MUEQ were assessed using exploratory factor analysis which resulted in the identification of 12 factors. The calculation of internal consistency and cross validation provided evidence of reliability and lack of redundancy of items.

Conclusion: Neck and shoulder complaints are more frequently reported among Dutch computer workers than arm, elbow and hand complaints. The results further indicate that the MUEQ has satisfactory reliability and internal consistency when used to document CANS among computer workers in the Netherlands.
\end{abstract}




\section{Background}

Complaints of arm, neck and shoulder (CANS) were recognized in the early seventies as an important cause of work disability. They were introduced as "occupational cramps" or "occupational myalgia" and suspected of being associated with numerous occupations and work activities [1]. The rapid development of information technology has entailed changes in working life during the recent decades. It is estimated that more than half of the working population in Western societies currently use personal computers at work [2]. Additionally, the relative time spent in front of the computer and the use of a computer mouse has increased rapidly over the years. It is likely that these developments may have contributed to the increasing burden of CANS [3].

The term CANS is introduced in the Netherlands and indicates "musculoskeletal complaints of arm, neck and/or shoulder not caused by acute trauma or by any systemic disease" [4]. CANS may cause severe and debilitating symptoms such as pain, numbness, and tingling. It may further result in reduced worker productivity, inability to perform job tasks and an increase in workers compensation costs [1]. In the Netherlands alone the incidences of CANS vary between 20 and $40 \%$ a year [5]. In the USA, the Bureau of Labour Statistics estimated that in 1996 64\% of all new work-related disability cases were related to CANS [6]. Research efforts on the identification of risk factors for the development of work-related CANS [5,7], has shown that these complaints may not be caused solely by high physical job demands (such as repetitive movements, awkward posture etc.) but also by psychosocial demands (such as low social support, high job demands etc.) [8]. At the current stage, the exact relationship between these risk factors and the development CANS is still not clear [9] and more research is needed.

The identification of risk factors for the development of CANS before they develop into a disabling musculoskeletal complaints is an important step in order to recognize relevant subgroups who have a high risk profile for CANS and also, in the longer run, to develop targeted and effective screening and interventions. Hence, targeting computer workers as the selected case population on which to base and to develop measurement tools specifying the risk factors of CANS would seem the appropriate first step.

Although there is an impressive body of literature with regard to measurement tools [10-12], nevertheless there is a need for developing a non complicated yet comprehensive questionnaire for the assessment of CANS [13]. We selected several items related to the presence of CANS from the Karasek Job Content Questionnaire (JCQ) which had been used already in other studies on risk factors for upper extremity complaints [14-16]. Additional, items were selected from the standardised Dutch Musculoskeletal Questionnaire (DMQ) [10,17]. The current study aims to present a questionnaire that would address the occurrence, nature and possible work-related physical and psychological risk factors of CANS among computer users with known psychometric properties. For this purpose a population of Dutch office workers was chosen. This paper presents the one-year prevalence rates of CANS in this working population and the psychometric properties (i.e. factor structure and reliability) of this questionnaire.

\section{Methods}

\section{Study population and data collection}

Study data were derived from a longitudinal cohort study which was conducted in 2002 among 600 office workers at the GAK (National Social Security Institution). Workers who perform computer office tasks (i.e. administrative, graphical and data entry tasks) were invited to participate in the study. The GAK Netherlands is a public benefits agency for statutory regulations in the field of sickness, incapacity for work and unemployment. The GAK carries out a number of national social insurances. It has several branches in the country of which two were selected in Maastricht and Heerlen, both towns in the south-east region of the Netherlands. Data were collected with selfadministered postal questionnaires. In mid December 2001 the questionnaires were distributed by internal mail of the GAK. Participants were asked to fill out the questionnaire and return it using the enclosed envelope. By mid January 2002 a reminder letter was sent to non responders, and the $4^{\text {th }}$ of February 2002 was set as the latest return date. Completed and returned questionnaires were coded and entered in the SPSS software program and data were cleaned and made ready for statistical analysis.

\section{The questionnaire}

The Maastricht Upper Extremity Questionnaire (MUEQ) Appendix 1 [see Additional file 1] assesses the occurrence and nature of CANS in computer workers and its associated physical and psychosocial risk factors. The MUEQ consists of 95 questions and has a completion time of approximately 20 minutes. The questionnaire covers the socio-demographic characteristics (age, gender, and employment status), as well as six main domains: i.e. (1) work station; (2) posture during work; (3) quality of break time; (4) job demands; (5) job control, and (6) social support. In addition, a number of items assess the quality of the work environment and the frequency and nature of extremity complaints, in the neck, shoulder, upper and lower arm, elbow, hand and wrist. Further, several items specified the clinical manifestations of the complaint: i.e. tingling, numbness, weakness, swelling, stiffness, fatigue, continuous pain and change in skin colour or temperature. The questions included in the MUEQ were partly derived from already existing instruments and partially 
developed by the authors themselves based on comprehensive study of the scientific and also grey literature. The items referring to potential psychosocial risk factors were based on the Job Content Questionnaire (JCQ) by Karasek et al [12]. The JCQ is a questionnaire-based instrument designed to measure the "content" of a respondent's work task(s) in a general manner. The questionnaire scales have been used to predict job related stress and coronary heart disease [12]. The MUEQ measures the key components of the job demand-control-support model by Karasek, namely skill discretion, decision authority, job demand and social support from supervisor and coworkers. Several items on physical work related risk factors were based on the Dutch Musculoskeletal Questionnaire (DMQ) by Hildebrandt et al [10]. As the present study is interested in measuring both the physical as well as the psychological workplace risk factors and because the psychometric properties of the JCQ and the DMQ independently have already been fairly well-established in other working populations $[18,19]$. Only items related to the presence of CANS were selected and combined in order to be included in the MUEQ.

The "complaint cases" were identified as participants who had complaints in at least one upper extremity body region for a minimal duration of one week during the preceding 12 months. All items were rephrased as statements in either a five point scale (completely true-completely false) and (always-never) or a dichotomous statement (yes-no). A simple English translation is presented in Appendix 1 [see Additional file 1] and the complete Dutch questionnaire is presented in Appendix 2 [see Additional file 1]. The English translation, as presented in Appendix 1, has not gone through a formal cross-cultural adaptation.

\section{Calculation of CANS prevalence rate}

All statistical analyses were performed with the SPSS 12.0 software package. Prevalence rates of complaints over the past twelve months that lasted for at least one week were computed for each upper musculoskeletal body region (neck, shoulder, arm, elbow, hand and wrist) including $95 \%$ confidence intervals (CI).

\section{Factor analysis}

Exploratory factor analysis was chosen as an appropriate approach since we aimed to analyse interrelations among a large number of items (questions) while trying to explain these variables in terms of their common underlying dimensions within each of the six domains $[13,20]$. The responses on various questions were conducted using Principal Component Analysis (PCA) with Varimax rotation. The number of factors retained was derived by considering the magnitude of the eigenvalues, Kaiser's (1960) eigenvalues [greater than 1] rule, the proportion of vari- ance extracted, item content, and the interpretability of the resulting factors. Independent factors were considered as meaningful when they appeared before the break in the Scree plot results. As for factor loading after the Varimax rotation, items with a factor loading less then 0.5 on all factors were excluded, unless they represent an essential assumption. Further, each factor had to be comprised of at least three items. If the results indicated more than two factors then a forced two factor analysis was performed [13].

\section{Reliability and internal consistency of the questionnaire}

The factor analysis assisted in exploring the different underlying factors (i.e. scales) within the different domains covered by the MUEQ. These scales may represent risk factors for the development of CANS.

One way to investigate the reliability of each scale is by calculating measures which indicate the internal consistency (i.e. homogeneity) of the items that form the scale. We investigated the internal consistency by calculating Cronbach's $\alpha$ for each scale and by calculating item-total correlations. Cronbach's $\alpha$ is a measure of how well each individual item in a scale correlates with the sum of the remaining items. An alpha greater than 0.70 was considered acceptable, this indicated that the individual items are independent but belong to the same scale. Optimal item-total correlation was considered to be between 0.2 and 0.5. Items with scores falling out of this range were examined for possible exclusion from the MUEQ [21].

\section{Performance of cross-validation}

In order to test the stability of the factor structure crossvalidation was carried out. This means that the results of both factor analysis and internal consistency analysis of one part of the data set are tested against the total data set, to ascertain that the two parts are as comparable as possible. The sub-sample was randomly selected from the study population and the comparison was made.

\section{Results}

\section{Demographic characteristics of the study population}

Two hundred and sixty four men and women out of the 600 responded to the baseline questionnaire which resulted in a response rate of $44 \%(n=264)$. Questionnaires were filled out by an almost equal numbers of men $(\mathrm{n}=133)$ and women $(\mathrm{n}=131)$. The percentage of respondents working five days per week was higher among men $(90 \%)$ than women $(60 \%)$. Nevertheless, $55 \%$ of the women worked 6 to 8 hours per day with a computer in comparison to $44 \%$ of the men (Table 1).

The data screening procedure showed no out of range cases. Moreover, all percentages of missing values were under $2 \%$ and scattered, and no systematic pattern was 
Table I: Descriptive characteristics of the study population $(n=264)$

\begin{tabular}{lll}
\hline & Male $(\mathrm{n}=133)$ & Female $(\mathrm{n}=13 \mathrm{I})$ \\
\hline Gender & $50.4 \%$ & $49.6 \%$ \\
\hline Number of days working/Week & & \\
3 & $0.8 \%$ & $15.3 \%$ \\
4 & $8.3 \%$ & $21.4 \%$ \\
5 & $90.2 \%$ & $59.5 \%$ \\
\hline Working 8 hours/Day & $85.0 \%$ & $66.4 \%$ \\
\hline Working 6 to 8 hours with computer/Day & $44.4 \%$ & $55.7 \%$ \\
\hline Number of working years in current position & & \\
$<1$ & $20.3 \%$ & $23.7 \%$ \\
$1-5$ & $41.4 \%$ & $43.5 \%$ \\
$5-10$ & $18.8 \%$ & $14.5 \%$ \\
$10-15$ & $9.0 \%$ & $8.4 \%$ \\
$>15$ & $10.5 \%$ & $9.2 \%$ \\
\hline
\end{tabular}

identified. Hence, the missing values were ignored. To examine whether the scores on the six main domains had a normal distribution, skewness and kurtosis of the domains were examined. The results (data not shown) indicated that there was no substantial deviation from normality in any of the main domains.

\section{Prevalence rates of CANS}

Prevalence rates of CANS during the previous year that lasted at least one week are presented in table 2 . The oneyear prevalence rate of CANS indicated that $54 \%$ of the respondents reported at least one complaint in the arm, neck and shoulder of which $48 \%$ were male and $61 \%$ females. The most commonly reported complaints were neck and shoulder symptoms (33\% and 31\% respectively), followed by upper arm complaints and hand $(12 \%$ and $11 \%)$, lower arm, wrist and elbow complaints (8\%, 8\% and $6 \%)$.
The distribution of complaint by anatomical locality (i.e. left side, right side and both sides) classified by gender is presented in table 3 The results indicated that "right side" complaints are more frequently reported than "left side" complaints or "both sides" complaints. Exceptions were shoulder complaints at "both sides" which were more frequently reported than complaints localized on the right or left side (Table 3).

Further, females reported higher prevalence rates for the various upper extremity anatomical areas (figure 1 ). The difference in the prevalence rates for neck and shoulder complaints between males and females were statistically significant (Table 2).

\section{Results of the cross-validation}

We found that the number of factors, the factor structure and factors loadings were for the greater part comparable between the first randomly created sub-sample and the

Table 2: Prevalence rates of upper extremity musculoskeletal complaints during the previous year that lasted at least one week

\begin{tabular}{|c|c|c|c|c|}
\hline Localization of complaints & $\begin{array}{l}\text { Total Number of subjects } \\
\text { with complaints }\end{array}$ & $\begin{array}{l}\text { Total Prevalence }(95 \% \mathrm{Cl}) \\
\qquad(\mathrm{n}=264)\end{array}$ & $\begin{array}{l}\text { Male Prevalence }(95 \% \mathrm{Cl}) \\
\qquad(\mathrm{n}=133)\end{array}$ & $\begin{array}{l}\text { Female Prevalence }(95 \% \\
\qquad \mathrm{Cl})(\mathrm{n}=13 \mathrm{I})\end{array}$ \\
\hline Neck complaints & 89 & $0.33(0.27$ to 0.39$)$ & $0.24(0.17$ to 0.31$)$ & $0.42(0.33$ to 0.50$)$ \\
\hline Shoulder complaints & 81 & 0.31 (028 to 0.37$)$ & 0.20 (0.13 to 0.27$)$ & $0.42(0.33$ to 0.50$)$ \\
\hline Upper arm complaints & 32 & $0.12(0.08$ to 0.16$)$ & $0.10(0.05$ to 0.15$)$ & $0.13(0.07$ to 0.18$)$ \\
\hline Elbow complaints & 16 & $0.06(0.03$ to 0.08$)$ & $0.07(0.03$ to 0.11$)$ & $0.04(0.01$ to 0.07$)$ \\
\hline Lower arm complaints & 21 & $0.08(0.05$ to 0.11$)$ & $0.06(0.02$ to 0.10$)$ & 0.09 (0.04 to 0.14$)$ \\
\hline Wrist complaints & 21 & $0.08(0.05$ to 0.11$)$ & $0.06(0.02$ to 0.10$)$ & $0.09(0.04$ to 0.14$)$ \\
\hline Hand complaints & 30 & 0.11 (0.07 to 0.15$)$ & $0.10(0.05$ to 0.15$)$ & $0.12(0.06$ to 0.17$)$ \\
\hline $\begin{array}{l}\text { Any upper extremity } \\
\text { complaint }\end{array}$ & 154 & $0.55(0.48$ to $06 \mathrm{I})$ & 0.48 . (0.06 to 0.39$)$ & $0.6 \mathrm{I} .(0.52$ to 0.69$)$ \\
\hline
\end{tabular}


Table 3: Percentages of upper extremity musculoskeletal complaints distributed by anatomical area

\begin{tabular}{|c|c|c|c|c|c|c|}
\hline \multirow{2}{*}{$\begin{array}{l}\text { Percentages \% } \\
\text { Male }(n=133)\end{array}$} & \multicolumn{6}{|c|}{ Localization of complaints } \\
\hline & $\begin{array}{l}\text { Shoulder } \\
\text { complaints }\end{array}$ & $\begin{array}{l}\text { Upper arm } \\
\text { complaints }\end{array}$ & Elbow complaints & $\begin{array}{l}\text { Lower arm } \\
\text { complaints }\end{array}$ & Wrist complaints & Hand complaints \\
\hline Left Side & 4.5 & 3.8 & 3.0 & 2.3 & 0.8 & 0.8 \\
\hline Right Side & 5.3 & 4.5 & 3.6 & 3.0 & 3.8 & 3.8 \\
\hline Both Sides & 10.5 & 2.3 & 0.8 & 0.8 & 1.5 & 6.0 \\
\hline \multicolumn{7}{|c|}{ Female $(n=|3|)$} \\
\hline Left Side & 12.2 & 5.3 & 0.8 & 3.1 & 2.3 & 1.5 \\
\hline Right Side & 7.6 & 6.1 & 3.1 & 3.8 & 2.3 & 4.6 \\
\hline Both Sides & 22.9 & 2.3 & 0.8 & 2.3 & 5.3 & 6.1 \\
\hline
\end{tabular}

total sample. Differences were found for two items within the social support domain. Item "I find support from my supervisors" loads higher on the (social support) subscale in the first random sample. However, the item loads higher on the (work flow) sub-scale in the total sample.
Further, the item "My work tasks depend on other colleagues" loads higher on the (work flow) sub-scale in the first sample but loads high on the (social support) subscale in the total sample.

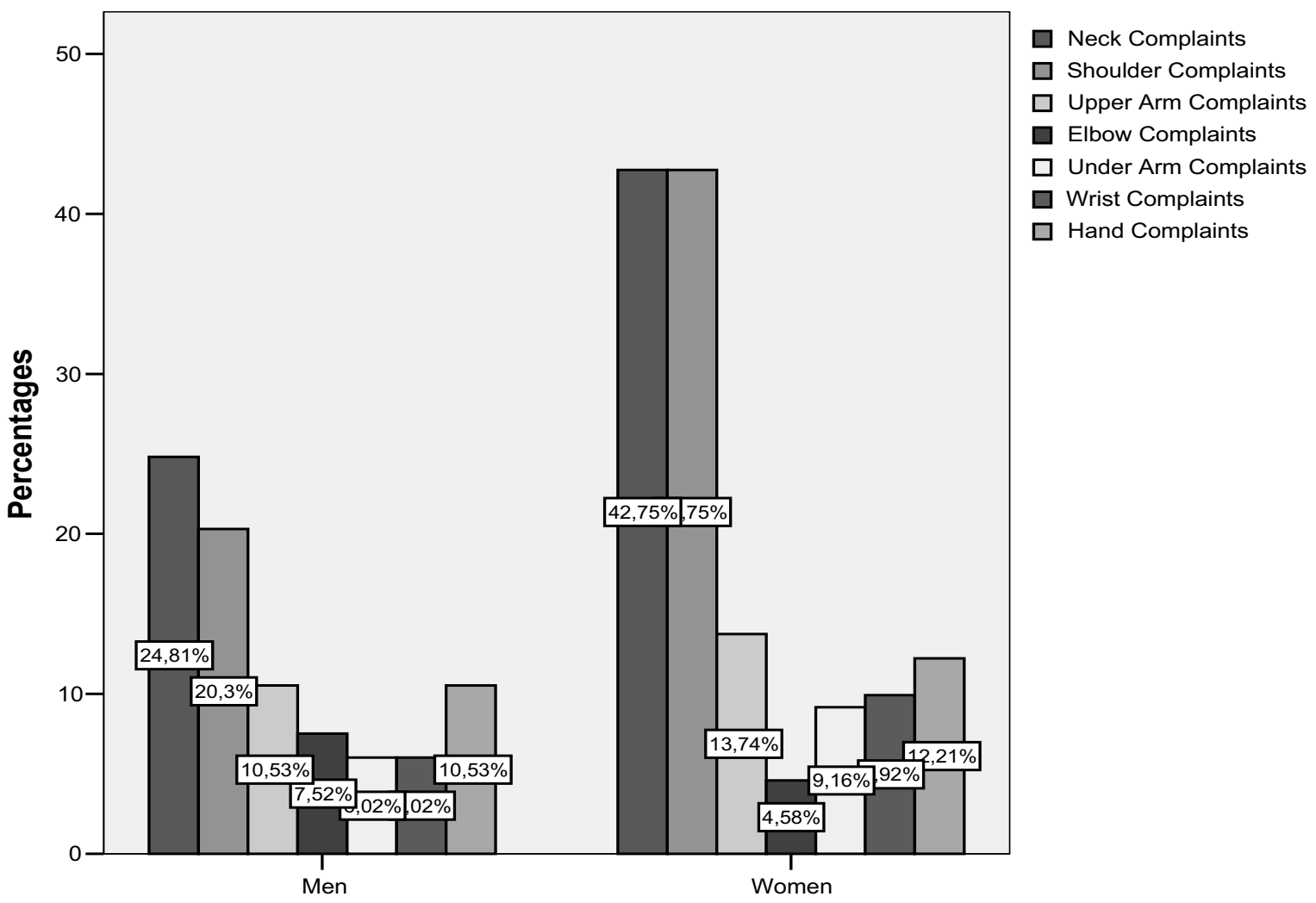

Gender

\section{Figure I}

Percentages of upper extremity musculoskeletal complaints with a minimal duration of one week over the preceding year in groups according to gender. 
Table 4: Factor loadings identified using principal component analysis and the orthogonal VARIMAX rotation *

\begin{tabular}{|c|c|c|c|}
\hline Domain & Abbreviated item description & Factor I & Factor 2 \\
\hline \multirow[t]{7}{*}{ Work Station } & & Office equipment & Computer position \\
\hline & Desk at work has suitable height & 0.80 & -0.06 \\
\hline & I can adjust my chair height & 0.62 & 0.16 \\
\hline & When I use the mouse my arm is supported & 0.50 & 0.16 \\
\hline & I have enough space to work at my desk & 0.66 & 0.16 \\
\hline & Keyboard is placed directly in front of me & 0.14 & 0.87 \\
\hline & Screen is placed directly in front of me & 0.05 & 0.77 \\
\hline Eigenvalue & & 1.84 & 1.28 \\
\hline$\%$ of Variance & & 26.1 & 18.3 \\
\hline \multirow[t]{9}{*}{ Body Posture } & & Awkward body posture & Head and body posture \\
\hline & I sit for long hours in one position & 0.59 & 0.12 \\
\hline & I sit with lifted shoulders. & 0.72 & 0.10 \\
\hline & Sitting in awkward posture & 0.71 & 0.27 \\
\hline & Performing repetitive tasks & 0.77 & 0.02 \\
\hline & Job physically exhausting & 0.50 & 0.06 \\
\hline & Head is twisted towards the left or right & 0.30 & 0.74 \\
\hline & Trunk is twisted towards the left or right & 0.08 & 0.82 \\
\hline & I sit in asymmetrical position & 0.26 & 0.61 \\
\hline Eigenvalue & & 3.30 & 1.45 \\
\hline$\%$ of Variance & & 30.0 & 13.9 \\
\hline \multirow[t]{10}{*}{ Job Control } & & Decision authority & Skill discretion \\
\hline & I decide how to perform my job task & 0.74 & 0.04 \\
\hline & I participate with others in decision & 0.71 & 0.32 \\
\hline & I decide my own task changes & 0.68 & 0.39 \\
\hline & I determine the time $\&$ speed job tasks & 0.55 & 0.12 \\
\hline & I solve work problems by my self & 0.74 & 0.04 \\
\hline & My work develop my abilities & 0.28 & 0.62 \\
\hline & At work I learn new things & 0.05 & 0.68 \\
\hline & Creative in my work & 0.16 & 0.66 \\
\hline & I undertake different tasks in my work & 0.05 & 0.67 \\
\hline Eigenvalue & & 3.32 & 1.33 \\
\hline$\%$ of Variance & & 36.9 & 14.4 \\
\hline \multirow[t]{8}{*}{ Job Demands } & & Work pressure & Task complexity \\
\hline & Work under extensive pressure & 0.76 & 0.10 \\
\hline & Difficulty to finish my job tasks & 0.83 & 0.24 \\
\hline & I take extra hours to finish & 0.70 & 0.11 \\
\hline & I speed to finish my tasks & 0.59 & 0.26 \\
\hline & No enough time to finish my job & 0.73 & 0.02 \\
\hline & I find my work tasks difficult & 0.06 & 0.92 \\
\hline & I have too many job tasks & 0.23 & 0.89 \\
\hline Eigenvalue & & 3.225 & 1.36 \\
\hline$\%$ of Variance & & 46.5 & 19.5 \\
\hline \multirow{9}{*}{$\begin{array}{l}\text { Social } \\
\text { Support }\end{array}$} & & Social support & Work flow \\
\hline & My work sphere is good & 0.69 & 0.14 \\
\hline & I find support from colleges & 0.65 & 0.56 \\
\hline & I find support from supervisors & 0.84 & 0.16 \\
\hline & My colleagues are friendly & 0.85 & 0.18 \\
\hline & My supervisors are friendly & 0.63 & 0.47 \\
\hline & Work tasks depend on other colleges & 0.51 & 0.62 \\
\hline & The work flow goes smoothly & 0.08 & 0.76 \\
\hline & I can ask \& enquire in my work & 0.15 & 0.74 \\
\hline Eigenvalue & & 3.96 & 1.04 \\
\hline$\%$ of Variance & & 49.9 & 13.0 \\
\hline
\end{tabular}


Table 4: Factor loadings identified using principal component analysis and the orthogonal VARIMAX rotation * (Continued)

\begin{tabular}{llll}
\hline Break Time & I can plan my work breaks & Autonomy & Break quality \\
& I can divide my work time & 0.82 & 0.1 I \\
& I can decide when to take a break & 0.76 & 0.02 \\
& I alternate in my body posture & 0.76 & 0.12 \\
& I alternate in my job task & 0.07 & 0.76 \\
& I perform job task without computer & 0.20 & 0.82 \\
Eigenvalue & After two hours I take a break for I0 min & 0.39 & 0.53 \\
\% of Variance & & 0.03 & 0.57 \\
\hline
\end{tabular}

* Only items with a factor loading $>0.5$ on at least one factor are reported

Since no important differences were found in the results we only present the results of the factor analyses as applied to the randomly created sub sample. Table 7 percentages of participants' response to each item for the six main domains

\section{Psychometric characteristics of the MUEQ Work station}

The first group of items addressed the work station domain (i.e. table, chair and computer position) and consisted of seven items. Three factors were extracted (data not shown) therefore, we undertook a forced two-factor solution. The rotated factor loadings of these analyses are shown in table 4. Examination of the factor loadings showed that one item "My chair support my lower back" load poorly on both factors and therefore was deleted.

The first factor included four items related to the "office equipment". This sub scale had a low Cronbach's alpha of 0.51 which is below the accepted norm of 0.70 [21] and values of item-total correlations were between 0.14 to 0.32 (Table 5 and 6). Two items (keyboard is placed directly in front of me and screen is placed directly in front of me) load convincingly on the second factor. They were grouped as "computer position" and this accounted for $18.3 \%$ of the total variance. Cronbach's alpha was 0.75 and item-total correlation of the sub-scale was 0.59 (Table 5 and 6$)$.

\section{Body posture}

The second domain addressed body posture and consisted of eleven items (Appendix 1). Two factors were extracted and examination of the rotated factor loadings showed that three items (when I key my hand is placed in a straight line with my lower arm, head is bent, and I keep a good work posture.) load poorly $(<0.5)$ on both factors. They were therefore excluded. Five items related to "awkward body posture" load highly on the first factor and this accounted for $30.0 \%$ of the total variance (Table 4 ). The scale had an acceptable Cronbach's alpha of 0.71 and item-total correlation of this scale ranged from 0.30 to 0.57 (Table 5 and 6). Furthermore, three items related to "head and body posture" load highly on the second factor and this accounted for $13.9 \%$ of the total variance. The scale had a low Cronbach's alpha of 0.54 and Item-total correlation of this scale ranged from 0.38 to 0.45 .

\section{Job control}

The job control domain included nine items. The Scree plot identified two factors; the rotated factor loadings indicated that the first factor "decision authority" contained five items (Table 4 ). This accounted for $36.9 \%$ of the total variance and Cronbach's alpha was 0.76 and the

Table 5: Internal consistency of the fourteen subscales

\begin{tabular}{lccc}
\hline Domain & Sub Scales & Internal consistency (Cronbach's $\alpha$ ) & Items numbers \\
\hline Work Station & Sub scale I: Office equipment & .51 & 10.11 .12 .16 \\
Body Posture & Sub scale 2: Computer position & .75 & 14.15 \\
& Sub scale 3: Awkward body posture & .71 & 18.19 .20 .21 .22 \\
Job Control & Sub scale 4: Head and body posture & .54 & 25.26 .27 \\
& Sub scale 5: Decision authority & .76 & 28.29 .30 .31 .32 \\
Job Demand & Sub scale 6: Skill discretion & .69 & 33.34 .35 .36 \\
Social Support & Sub scale 7: Work pressure & .80 & 37.38 .39 .40 .41 \\
& Sub scale 8: Task complexity & .84 & 42.43 \\
Break Time & Sub scale 9: Social support & .80 & 64.65 .66 .67 .68 \\
& Sub scale 10: Work flow & .60 & 61.62 .63 \\
& Sub scale II: Autonomy & .71 & 44.45 .46 \\
\end{tabular}


Table 6: Item-total correlation of the fourteen sub scales

\begin{tabular}{lccc}
\hline \multicolumn{1}{c}{ Domain } & Sub Scales & Item-total correlation (Min-Max) & Items numbers \\
\hline Work Station & Sub scale I: Office equipment & 0.14 to 0.32 & 10.11 .1216 \\
& Sub scale 2: Computer position & 0.59 & 14.15 \\
Body Posture & Sub scale 3: Awkward body posture & 0.30 to 0.57 & 18.19 .20 .21 .22 \\
& Sub scale 4: Head and body posture & 0.38 to 0.45 & 25.26 .27 \\
Job Control & Sub scale 5: Decision authority & 0.37 to 0.61 & 28.29 .30 .31 .32 \\
& Sub scale 6: Skill discretion & 0.28 to 0.51 & 33.34 .35 .36 \\
Job Demand & Sub scale 7: Work pressure & 0.50 to 0.75 & 37.38 .39 .40 .41 \\
Social Support & Sub scale 8: Task complexity & 0.54 & 42.43 \\
Break Time & Sub scale 9: Social support & 0.58 to 0.67 & 64.65 .66 .67 .68 \\
& Sub scale 10: Work flow & 0.28 to 0.38 & 61.62 .63 \\
& Sub scale II: Autonomy & 0.47 to 0.58 & 44.45 .46 \\
& Sub scale 12: Break quality & 0.39 to 0.60 & 47.48 .49 .50 \\
\hline
\end{tabular}

Item-total correlation ranged from 0.37 to 0.61 (Table 5 and 6 ). The second factor "skill discretion" contained four items (Table 4). These accounted for $14.4 \%$ of the total variance with Cronbach's alpha of 0.69 , which is below the accepted norm of 0.70 [21] and Item-total correlations ranging from 0.28 to 0.51 (Table 5 and 6 ).

\section{Job demands}

The job demands domain consisted of a total number of seven items (Appendix 1). The Scree plot applied to the data shows that two factors were to be retained. Examination of the rotated factor loading showed that two items (I find my work tasks difficult and I have too many job tasks) load high on the second factor. Although the factor holds less than three items they nevertheless covered an important assumption of worker's perception of job pressure and were therefore retained and labelled "task complexity". These factors accounted for $19.5 \%$ of the total variance (Table 4). Cronbach's alpha was 0.84 and the Item-total correlation was 0.54. The other five items (Table 4) constituted the "work pressure" scale which accounted for $46.5 \%$ of the total variance. Cronbach's alpha was 0.80 and the Item-total correlations ranged from 0.50 to 0.75 (Table 5 and 6).

\section{Social support}

Eight items investigated the relationship among co-workers and between workers and supervisors. The Scree plot indicated that two factors were meaningful enough to be retained. The rotated factor loadings indicated that five items load high on the first factor "social support" and this accounted for $49.9 \%$ of the total variance (Table 4 ). Cronbach's alpha had an acceptable level of 0.80 and item-total correlations of "social support" ranged from 0.58 to 0.67 . The other three items (the work flow goes smoothly, I can ask and enquire in my work, and work tasks depend on other colleges) were classified as the "work flow" and accounted for $13.0 \%$ of the total vari- ance. Cronbach's was 0.60 and item-total correlations ranged from 0.28 to 0.38 (Table 5 and 6 ).

\section{Break time}

Break time during working hours was investigated by eight items. The rotated factor loading, indicated that, one item (I find my work breaks sufficient) loads poorly on both factors and was deleted. The first factor holds three items which made the "autonomy" scale and this accounted for $35.5 \%$ of the total variance (Table 4 ). Cronbach's alpha was 0.71 and the item-total correlations of the autonomy scale ranged from 0.47 to 0.58 . Four items related to the "break quality" load highly on the second factor, accounting for $25.9 \%$ of the total variance, Cronbach's alpha of 0.70 and with item-total correlations ranging from 0.39 to 0.60 (Table 5 and 6 ).

\section{Discussion}

In the present sample of 264 subjects of computer office workers, we assessed the 12-months prevalence of CANS among a Dutch cohort of computer workers and tested a newly developed comprehensive questionnaire (MUEQ) that included various scales, which are hypothetically related to an increased risk for CANS. The results showed higher prevalence of neck and shoulder complaints in the study population compared to arm, elbow and hand complaints. This matter is rather debatable in the literature since some reviews, which focus on muscle activity during computer use, suggest a stronger relationship between computer use and complaints of the hand and arm, than to complaints of the neck and shoulders $[22,23]$. On the other hand, there are also studies indicating that neck or shoulder complaints are more common than other complaints in the upper extremity in computer workers $[1,9,22]$. Job characteristics, such as high quantitative job demands, having little influence on one's work situation, and limited rest break opportunities have been found as 
Table 7: Percentage of response option for each item listed in the main domains

\begin{tabular}{|c|c|c|c|c|c|}
\hline \multirow{2}{*}{$\begin{array}{l}\text { Items } \\
\text { Work Station }\end{array}$} & \multicolumn{5}{|c|}{ Percentage $\%$ of response $N=264$} \\
\hline & No & Yes & & & \\
\hline Desk at work has suitable height & 14.8 & 85.2 & & & \\
\hline I can adjust my chair height & 6.1 & 93.9 & & & \\
\hline When I use the mouse my arm is supported & 33.4 & 65.9 & & & \\
\hline I have enough space to work at my desk & 34.1 & 65.9 & & & \\
\hline Keyboard is placed directly in front of me & 18.6 & 81.4 & & & \\
\hline Screen is placed directly in front of me & 20.6 & 79.9 & & & \\
\hline Body Posture & Always & Often & Sometime & Seldom & Never \\
\hline I sit for long hours in one position & $40.1^{\circ}$ & 29.0 & 16.0 & 7.6 & 7.6 \\
\hline I sit with lifted shoulders. & 17.0 & 18.6 & 19.7 & 16.0 & 27.7 \\
\hline Sitting in awkward posture & 7.6 & 21.2 & 29.9 & 23.1 & 18.2 \\
\hline Performing repetitive tasks & 15.5 & 29.2 & 23.1 & 19.3 & 12.8 \\
\hline Job physically exhausting & 2.3 & 36.1 & 18.2 & 35.2 & 8.3 \\
\hline Head is twisted towards the left or right & 15.5 & 24.6 & 24 & 22.0 & 13.6 \\
\hline Trunk is twisted towards the left or right & 3.4 & 13.3 & 16.7 & 32.6 & 34.0 \\
\hline I sit in asymmetrical position & 5.3 & 15.2 & 16.7 & 32.6 & 34.1 \\
\hline \multicolumn{6}{|l|}{ Job Control } \\
\hline I decide how to perform my job task & 25.0 & 37.5 & 26.1 & 8.0 & 3.4 \\
\hline I participate with others in decision & 17.4 & 30.3 & 31.3 & 14.4 & 6.4 \\
\hline I decide my own task changes & 23.9 & 46.9 & 21.2 & 8.0 & 6.1 \\
\hline I determine the time \& speed job tasks & 26.9 & 37.9 & 13.0 & 3.0 & 1.9 \\
\hline I solve work problems by my self & 23.9 & 40.9 & 21.2 & 8.0 & 6.1 \\
\hline My work develop my abilities & 26.9 & 37.9 & 24.6 & 7.6 & 3.0 \\
\hline At work I learn new things & 44.7 & 37.3 & 13.0 & 3.0 & 1.9 \\
\hline Creative in my work & 30.3 & 30.7 & 25.8 & 8.7 & 4.5 \\
\hline I undertake different tasks in my work & 22.3 & 34.1 & 32.2 & 7.6 & 3.8 \\
\hline \multicolumn{6}{|l|}{ Job Demand } \\
\hline Work under extensive pressure & 12.9 & 34.1 & 40.5 & 10.2 & 2.3 \\
\hline Difficulty to finish my job tasks & 4.9 & 15.5 & 31.4 & 32.2 & 15.9 \\
\hline I take extra hours to finish & 2.7 & 8.3 & 22.7 & 28.8 & 37.5 \\
\hline I speed to finish my tasks & 6.1 & 21.2 & 42.4 & 22.7 & 17.0 \\
\hline No enough time to finish my job & 2.3 & 12.1 & 33.3 & 35.2 & 17.0 \\
\hline I find my work tasks difficult & 1.1 & 6.8 & 34.1 & 41.1 & 16.7 \\
\hline I have too many job tasks & 2.3 & 12.1 & 33.3 & 35.2 & 17.0 \\
\hline Social Support & Always & Often & Sometime & Seldom & Never \\
\hline My work sphere is good & 1.9 & 6.8 & 23.9 & 41.3 & 26.1 \\
\hline I find support from colleges & 4.6 & 8.3 & 22.3 & 33.3 & 31.3 \\
\hline I find support from supervisors & 8.0 & 16.3 & 30.7 & 28.0 & 17.0 \\
\hline My colleagues are friendly & 0.4 & 1.9 & 16.7 & 40.9 & 40.2 \\
\hline My supervisors are friendly & 2.3 & 4.5 & 20.1 & 39.8 & 33.3 \\
\hline Work tasks depend on other colleges & 6.8 & 14.8 & 33.7 & 33.7 & 11.0 \\
\hline The work flow goes smoothly & 10.2 & 18.2 & 34.1 & 28.4 & 9.1 \\
\hline I can ask \& enquire in my work & 4.5 & 10.2 & 21.2 & 38.6 & 25.4 \\
\hline \multicolumn{6}{|l|}{ Break Time } \\
\hline I can plan my work breaks & 26.1 & 35.2 & 17.0 & 13.6 & 8.1 \\
\hline I can divide my work time & 41.3 & 34.8 & 21.1 & 3.8 & 8.0 \\
\hline I can decide when to take a break & 29.1 & 37.5 & 19.3 & 9.5 & 3.8 \\
\hline I alternate in my body posture & 6.3 & 26.5 & 30.7 & 28.4 & 6.1 \\
\hline I alternate in my job task & 11.5 & 29.2 & 37.7 & 17.8 & 6.8 \\
\hline I perform job task without computer & 21.6 & 39.4 & 22.3 & 13.3 & 3.1 \\
\hline After two hours I take a break for $10 \mathrm{~min}$ & 5.3 & 11.0 & 18.6 & 22.0 & 40.2 \\
\hline
\end{tabular}


predictors of neck pain [24,25]. One should cautiously postulate that certain risk factors are more related to the presence of neck and shoulder pain than to wrist and hand pain. However, the majority of the available literature either investigates a variety of symptoms (frequency, intensity) and/or one body region or the used concepts are rather broadly defined which complicates making a meaningful comparison of the results presented in the literature [25]. However, the correlations between risk factor scales and CANS are to be investigated and presented in a separate manuscript.

Furthermore, musculoskeletal complaints and neck and shoulder complaints in particular, were more common among women than among men. Even though women and men were working in the same institute and had the same job titles. Another study [26] confirmed our findings, showing the prevalence of symptoms in the neck and upper extremities per year ??to be $51 \%$ among men and $72 \%$ among women. A possible explanation for this gender related difference is that women apparently do not always perform tasks with the same physical requirements or work organization as men. The European Foundation for the Improvement of Living and Working Conditions indicated that women tended to perform more repetitive work on average, whereas men were less likely to sit for prolonged periods compared to women (refer). Furthermore, women are more often exposed to additional stress from unpaid work such as housekeeping and child care $[18$, 26].

We have attempted to accurately examine the measurement properties of the MUEQ, but there are some aspects and limitations that merit discussion. The response rate of $44 \%$ was rather low. It is possible that a 95-item survey was too long for routine administration among workers. Hence, our results must be considered in light of the limitations associated with the study response rate.

The results of the factor analysis in the present study indicated that each domain included two scales accounting for approximately $50 \%$ of the variance. Identification of the domains can be gleaned from the pattern of the item loadings on the two scales. The factor loading was not difficult to interpret as there was a semantic relationship between the items that contribute to it. For instance, the job control domain was subdivided into a decision authority scale, which reflects worker's perception of their control in performing job task, and a skill discretion scale, which addresses information about skills needed to perform job tasks. The overlap between these two concepts was in line with Karasek's (1989) results which indicated that these two concepts are often combined as decision latitude [20]. However, the results of the present study gave reason to treat these control concepts as separate, yet related, concepts.

As for the reliability coefficient, Nunnally (1978) suggested a coefficient of at least 0.70 to be acceptable [13]. Cronbach's alpha coefficients for the majority of the subscales in the MUEQ were larger than 0.70. Some of the items in the social support and work station scales showed sub optimal item-total correlation (either below 0.2 or above 0.5 ). Cronbach's alpha did not improve sufficiently when items were removed to justify the omission of items from the scale.

The study abstained from calculating the internal consistency with regard to the quality of work environment domain because the meaning of the items included was too different in order to be clustered in one scale.

\section{Conclusion}

In conclusion, neck and shoulder complaints are reported more frequently than complaints in any of the other upper body regions. Further, women had higher 12months prevalence rates of upper extremity musculoskeletal complaints than men. The tested questionnaire, i.e. the MUEQ, has satisfactory reliability and internal consistency when used to document CANS among computer office workers in the Netherlands.

This questionnaire can be used as a screening inventory for occupational health services to identify worker groups in which a more thorough ergonomic analysis is indicated.

We tested the psychometric properties of the questionnaire in employees without severe musculoskeletal complaints. Further evaluation of the psychometric properties of the questionnaire studies in other populations may therefore be useful. The question whether the scales identified by the factor analyses are indeed risk factors for the development of CANS in computer workers needs to be addressed in well designed prospective cohort studies.

\section{Competing interests}

The author(s) declare that they have no competing interests.

\section{Authors' contributions}

S.E and J.B.S have made substantial contributions to conception and writing. S E did the data analysis and drafted the manuscript. J.K, P.H.G. L and $\mathrm{R}$ Bhave helped in designing the study questionnaire and critically revised the manuscript. All authors read and approved the final manuscript. 


\section{Additional material}

\section{Additional file 1}

Appendix 1 and 2 Maastricht Upper Extremity Questionnaire (MUEQ) Appendix 1 presents the English translated version of the MUEQ and Appendix 2 presents the original Dutch version.

Click here for file

[http://www.biomedcentral.com/content/supplementary/14712474-8-68-S1.doc]

\section{Acknowledgements}

We would like to thank the management, doctors and employees of the GAK (national unemployment insurance office) in Maastricht and Heerlen, the Netherlands, for their willingness to participate in this study.

\section{References}

I. Bergqvist U, Wolgast E, Nilsson B, Voss M: Musculoskeletal disorders among visual display terminal workers: individual, ergonomic, and work organizational factors. Ergonomics 1995 , 38:763-776.

2. Ruess L, O'Connor SC, Cho KH, Hussain FH, Howard WJ 3rd Slaughter RC, Hedge A: Carpal tunnel syndrome and cubital tunnel syndrome: work-related musculoskeletal disorders in four symptomatic radiologists. AJR Am J Roentgenol 2003 | 8 |:37-42.

3. Dembe $A E$ : The changing nature of office work: effects on repetitive strain injuries. Occup Med 1999, |4:6|-72, iii.

4. Huisstede BM, Miedema HS, Verhagen AP, Koes BW, Verhaar JA: Multidisciplinary consensus on the terminology and classification of complaints of the arm, neck and/or shoulder. Occup Environ Med 2007, 64:313-319.

5. Bongers PM, de Winter CR, Kompier MA, Hildebrandt VH: Psychosocial factors at work and musculoskeletal disease. Scand J Work Environ Health 1993, 19:297-312.

6. Gerr F, Marcus M, Monteilh C: Epidemiology of musculoskeletal disorders among computer users: lesson learned from the role of posture and keyboard use. J Electromyogr Kinesiol 2004, | 4:25-3I.

7. Guidotti TL: Occupational repetitive strain injury. Am Fam Physician 1992, 45:585-592.

8. van den Heuvel SG, van der Beek AJ, Blatter BM, Hoogendoorn WE, Bongers PM: Psychosocial work characteristics in relation to neck and upper limb symptoms. Pain 2005, I | 4:47-53.

9. Bongers PM, Kremer AM, ter Laak J: Are psychosocial factors, risk factors for symptoms and signs of the shoulder, elbow, or hand/wrist?: A review of the epidemiological literature. Am J Ind Med 2002, 4I:3 I5-342.

10. Hildebrandt VH, Bongers PM, van Dijk FJ, Kemper HC, Dul J: Dutch Musculoskeletal Questionnaire: description and basic qualities. Ergonomics 2001, 44:1038-1055

II. van der Doef M, Maes S: The Leiden Quality of Work Questionnaire: its construction, factor structure, and psychometric qualities. Psychol Rep 1999, 85:954-962.

12. Karasek R, Brisson C, Kawakami N, Houtman I, Bongers P, Amick B The Job Content Questionnaire (JCQ): an instrument for internationally comparative assessments of psychosocial job characteristics. J Occup Health Psychol 1998, 3:322-355.

13. Bot SD, Terwee CB, van der Windt DA, Feleus A, Bierma-Zeinstra SM, Knol DL, Bouter LM, Dekker J: Internal consistency and validity of a new physical workload questionnaire. Occup Environ Med 2004, 6 I:980-986.

14. Leroux I, Dionne CE, Bourbonnais R: Psychosocial job factors and the one-year evolution of back-related functional limitations. Scand J Work Environ Health 2004, 30:47-55.

15. Kaergaard A, Andersen $\mathrm{H}$ : Musculoskeletal disorders of the neck and shoulders in female sewing machine operators: prevalence, incidence, and prognosis. Occup Environ Med 2000, 57:528-534.
16. Helmhout PH, Harts CC, Staal JB, de Bie RA: Rationale and design of a multicenter randomized controlled trial on a 'minimal intervention' in Dutch army personnel with nonspecific low back pain [ISRCTN I 93343 I 7]. BMC Musculoskelet Disord 2004, 5:40.

17. ljmker S, Huysmans M, Blatter BM, van der Beek AJ, van Mechelen W, Bongers PM: Should office workers spend fewer hours at their computer? A systematic review of the literature. Occup Environ Med 2006.

18. S IJ, Blatter BM, van der Beek AJ, van Mechelen W, Bongers PM: Prospective research on musculoskeletal disorders in office workers (PROMO): study protocol. BMC Musculoskelet Disord 2006, 7:55

19. de Vet HC, Ader HJ, Terwee CB, Pouwer F: Are factor analytical techniques used appropriately in the validation of health status questionnaires? A systematic review on the quality of factor analysis of the SF-36. Qual Life Res 2005, I4:1203-I8; dicussion $1219-21$, 1223-4.

20. Streiner DL: Starting at the beginning: an introduction to coefficient alpha and internal consistency. J Pers Assess 2003, 80:99-103.

21. Fredriksson K, Alfredsson L, Koster M, Thorbjornsson CB, Toomingas $A$, Torgen $M$, Kilbom $A$ : Risk factors for neck and upper limb disorders: results from 24 years of follow up. Occup Environ Med 1999, 56:59-66.

22. Korhonen $\mathrm{T}$, Ketola $\mathrm{R}$, Toivonen $\mathrm{R}$, Luukkonen $\mathrm{R}$, Hakkanen $\mathrm{M}$, Viikari-Juntura E: Work related and individual predictors for incident neck pain among office employees working with video display units. Occup Environ Med 2003, 60:475-482.

23. Bongers PM, ljmker S, van den Heuvel S, Blatter BM: Epidemiology of work related neck and upper limb problems: psychosocial and personal risk factors (part I) and effective interventions from a bio behavioural perspective (part II). J Occup Rehabil 2006, 16:279-302.

24. Punnett L, Bergqvist U: Musculoskeletal disorders in visual display unit work: gender and work demands. Occup Med 1999 , 14: I 13-24, iv.

\section{Pre-publication history}

The pre-publication history for this paper can be accessed here:

http://www.biomedcentral.com/1471-2474/8/68/prepub
Publish with Bio Med Central and every scientist can read your work free of charge

"BioMed Central will be the most significant development for disseminating the results of biomedical research in our lifetime. "

Sir Paul Nurse, Cancer Research UK

Your research papers will be:

- available free of charge to the entire biomedical community

- peer reviewed and published immediately upon acceptance

- cited in PubMed and archived on PubMed Central

- yours - you keep the copyright
BioMedcentral 